\title{
Burnout among frontline health professionals in two African countries: a cross sectional study from Egypt and Sudan
}

Noha Ahmed El Dabbah

Alexandria University https://orcid.org/0000-0001-6321-9219

Yasir Ahmed Mohammed Elhadi ( $\square$ hiph.yelhadi@alexu.edu.eg )

Alexandria University https://orcid.org/0000-0003-3649-0374

\section{Research Article}

Keywords: Burnout, Oldenburg, COVID 19, isolation facilities, healthcare professionals

Posted Date: September 30th, 2021

DOI: https://doi.org/10.21203/rs.3.rs-951355/v1

License: (c) (1) This work is licensed under a Creative Commons Attribution 4.0 International License.

Read Full License 


\section{Abstract}

\section{Background}

The impact of coronavirus pandemic (COVID19) on healthcare professionals (HCPs) is an issue of global concern. Occupational burnout among HCPs has been reported by several studies. However, pandemicrelated burnout needs further investigation especially among frontline HCPs. This study aimed to investigate the prevalence and associated factors of burnout syndrome among HCPs working at COVID19 isolation facilities in Egypt and Sudan.

\section{Methods}

A cross-sectional survey was conducted among frontline HCPs in Egypt and Sudan from May 2021 to July 2021. An online, anonymous, self-administered questionnaire was used for data collection. Occupational burnout was estimated using the Oldenburg Burnout Inventory. Data analyzed using SPSS software.

\section{Results}

A total of 362 HCPs participated in the study and were equally recruited from Egypt (181) and Sudan (181) with mean age of $(31.84 \pm 8.32)$ years. More than half were females $(60 \%)$ and were physicians (58.3\%). Most healthcare professionals included in the study had high levels of work disengagement (75.4\%) and emotional exhaustion (98.6\%). Burnout syndrome was present in $75 \%$ of the HCPs with $77 \%$ prevalence among Egyptian HCPs and 71\% prevalence among Sudanese HCPs. The parameters that are associated with burnout syndrome among Egyptian HCPs were working hours per week; while for Sudanese HCPs, these were age and number of days off.

\section{Conclusion}

The study revealed a high prevalence of burnout syndrome among HCPs working at COVID-19 isolation facilities in Egypt and Sudan. Appropriate actions should be taken to preserve mental health status of HCPs through establishment of effective and efficient coping strategies.

\section{Introduction}

The Coronavirus disease (COVID-19) has threatened global heath and sustainable development, it was declared a global pandemic by the World Health organization in March 2020 with the numbers of confirmed cases and deaths have been escalating since that time until the virus reached to almost all countries. ${ }^{1,2}$ The global pandemic has posed unprecedented challenges to health systems worldwide, leading to considerable impact on healthcare delivery, including the cessation of routine services, service rationings, repurposing of clinical areas and assigning health care staff to new tasks within unfamiliar 
high-risk clinical environments. ${ }^{3}$ Pandemics pose enormous psychological burden on healthcare professionals (HCPs) as they are required to work under stressful conditions, make rapid ethical decisions, with the constantly changing guidelines. They also experience excessive workload while facing rising demands emanating from insufficient human and non-human resources, besides having personal anxiety from contracting the disease or passing infection to their families. ${ }^{3,4}$ Herbert Freudenberger ${ }^{5}$, a psychologist in 1970s declared burnout as 'a state of mental exhaustion caused by one's professional life' that consists of three salient features; (i) emotional exhaustion and feelings of energy depletion; (ii) depersonalization with a feeling of negativism or cynicism towards the job; and (iii) a reduced sense of accomplishment or success with the tendency of the worker to negatively evaluate themselves and showing dissatisfaction with their own performance at work. ${ }^{6,7}$ defined by the World Health Organization in the $11^{\text {th }}$ revision of the International Classification of Diseases (ICD-11); "Burnout is a syndrome resulting from chronic workplace stress that has not been successfully managed". ${ }^{8}$ Most burnout concept models emphasize that burnout covers the two main core symptoms of high levels of exhaustion and depersonalization with considering the reduced accomplishment as a complication of exhaustion rather than a cause. . $^{6}$

The causes of burnout are classified according to organizational or individual features. Organizational features such as excessive workload, long working hours, deficient rest and loss of control in one's profession, low perceived social support, work politics and fair management within the organization are expressed by the chronic persistent unresolved work-related stress. While individual features are linked to individual characteristics such as ineffective coping strategies and improper handling of occupational stress, vulnerable HCPs with traits include idealism, perfectionism and a high sense of responsibility, early career HCPs facing unrealistic expectations, declining patient health or patients' aggression. Long term contact with patient and development of family-like relations may also result in emotional detachment and burnout. $6,9,10$

The consequences of burnout affect HCPs, patients and organizations. Consequences on HCPs include the potential unemployment, early retirement or career termination, sickness, injury, accidents, financial loss, more family and personal relationship conflicts, decreased job satisfaction, poor health outcomes such as depression, frequent headaches, insomnia, anxiety and becoming offensive or violent at work with higher suicide rates. The organizational and patient consequences of burnout are the increased staff turnover, absenteeism, decreased productivity, self-reported suboptimal patient care practices, compromising patient safety and higher rates of medical errors. ${ }^{11,12}$

Healthcare professionals at the frontline of the battle against COVID-19 pandemic have been exposed to a variety of physical and psychological stressors during the COVID-19 pandemic, which could lead to burnout syndrome. ${ }^{13}$ Burnout is becoming more widely recognized among HCPs during COVID-19 outbreak. For instance, a global survey of burnout syndrome during COVID-19 pandemic among HCPs from 60 countries showed that more than half $(51 \%)$ of HCPs experienced burnout. ${ }^{14}$ In the Middle East, the prevalence of occupational burnout among HCPs was reported to be between $40 \%$ and $60 \% .{ }^{15}$ In 
Low- and middle-income countries among HCPs working at COVID-19 isolation facilities, burnout negatively affects motivation and may further reduce productivity of the already limited staff, ${ }^{16}$ leading to emotional exhuation, insomnia, and fear. ${ }^{17}$

Burnout syndrome is a real cause for concern in African health facilities. The burden of providing quality care services with limited means to a large number of patients can lead to high rates of burnout. ${ }^{18}$ Egypt and Sudan, both are developing African countries suffering weak health care systems with limited human and non-human resources in the face of COVID-19 pandemic. ${ }^{19}$ Within these circumstances, the response of HCPs to COVID-19 pandemic would be challenging and the psychological impacts could be augmented. Nevertheless, few Egyptian and no Sudanese studies have examined burnout prevalence among this critical population in both countries, this study aimed to investigate the prevalence and associated factors of burnout syndrome among HCPs working at COVID-19 isolation facilities in Egypt and Sudan.

\section{Methods}

\subsection{Study design and sampling}

Participants were recruited through a non-probability snowball sampling; each HCP participant has invited colleagues to participate. The sample size was calculated through Epi Info 7 software based on $13 \%$ expected prevalence of burnout syndrome among HCPs dealing with COVID-19 cases, ${ }^{13,20}$ and using alpha error of 0.05 and margin of error $5 \%$ computing a minimum required sample of 174 participants from each country. The total number pf participants collected from both countries were 362 . Since the study was conducted amidst COVID-19 pandemic within strict isolation policy that calls for reducing the face-to-face contact, a cross-sectional internet-based survey was conducted for three months starting from May 2021 till the end of July 2021. The online survey form was created using Google Forms and a link to the electronic questionnaire was distributed to respondents across social media platforms; Facebook and WhatsApp that are exclusive for HCPs working at COVID-19 isolation facilities in Egypt and Sudan, as used in previous surveys of HCPs during the pandemic. ${ }^{21}$ Admins of these groups were contacted and asked to circulate and post the questionnaire on their groups and among their HCPs. Physicians, nurses, pharmacists and paramedical technicians of different specialties working at COVID19 isolation facilities in Egypt and Sudan at the time of data collection were invited to participate in the study, submit and distribute the online questionnaire. The reception of the filled questionnaires was stopped when the target sample size had been achieved.

\subsection{Survey tool and data collection}

Anonymous Google form, self-administered questionnaire was used for data collection. The required data related to sociodemographic and professional characteristics (country, age, sex, marital status, educational qualification, profession and specialty, days off, and working hours/week) were collected. Occupational burnout was estimated using Oldenburg Burnout Inventory (OLBI). The OLBI is a validated 
tool for the investigation of burnout, it consists of sixteen items ; eight of the questions are related to emotional exhaustion and eight for job disengagement. Items comprise both positively and negatively phrased questions recorded on a four-point Likert scale ranging from 1 to 4 (Strongly agree - Strongly disagree) with four points for the highest burnout response and one point for the lowest. ${ }^{22}$ Participants were considered to be "at high risk of burnout" if they met the thresholds of 2.1 for the exhaustion subscales and 2.25 for disengagement subscales. ${ }^{23,24}$ OLBI outcomes were defined by four subscale scores that are calculated as the mean of the item scores for each subscale, categorized as follows: ${ }^{25-27}$

Burnout - High exhaustion score $\geq 2.25$ and high disengagement score $\geq 2.1$

Exhausted - High exhaustion score $\geq 2.25$ and low disengagement score $<2.1$

Disengaged - High disengagement score $\geq 2.1$ and low exhaustion score $<2.25$

No burnout - Low exhaustion score $<2.25$ and low disengagement score $<2.1$

The OLBI items were translated to Arabic by the researchers, the questionnaire was piloted on $30 \mathrm{HCPs}$ to examine understandability and face validity. The Internal consistency of OLBI subscales was measured using Cronbach alpha. For the 8 items of disengagement Cronbach alpha was 0.700 , and for the 8 items of exhaustion was 0.855 and for the overall burnout of the total 16 items Cronbach alpha was 0.877 which are considered acceptable. ${ }^{28}$ The final questionnaire was distributed virtually through social media platforms that are exclusive for HCWs working at COVID-19 isolation hospitals in Egypt, and Sudan.

\subsection{Statistical analysis of the data}

Data were fed to the computer and analyzed using IBM SPSS software package version 20.0. (Armonk, NY: IBM Corp). The Kolmogorov- Smirnov test was used to verify the normality of distribution of variables. Mean with standard deviation, and frequencies with percent were used to describe the numerical and categorical data respectively. Student's t-test was used to compare the means between two groups for normally distributed quantitative variables. ANOVA was used for comparing the means between more than two groups. Univariate and multivariate regression analysis was conducted for identifying the independent sociodemographic and work parameters affecting burnout syndrome. All results were considered statistically significant when the significant probability was less than $5 \%(p<$ 0.05).

\subsection{Ethical considerations}

This study has been approved by the Ethics and Technical Committee of the High Institute of Public Health, Alexandria University on May 2021. The purpose of the research was stated at the beginning of 
the questionnaire and consent to participate was included in the survey tool. Also, participants were able to withdraw from the survey any time before its completion. Participants' answers were anonymous and confidential. Participants were not permitted to provide their names or contact information.

\section{Results}

\subsection{Socio-demographic and professional characteristics of participants}

Table (1) shows the distribution of the study HCPs according to their sociodemographic and work characteristics. Three hundred and sixty-two HCPs participated in the study and were equally recruited from Egypt (181) and Sudan (181) with mean age (standard deviation[SD]) of the whole sample $31.84 \pm$ 8.32 years or $37.0 \pm 7.55$ years for Egypt, and $26.67 \pm 5.31$ years for Sudan. More than half of study HCPs were females (60\%), 50.3\% were single and 55\% completed a bachelor degree. Physicians constituted $58.3 \%$ of the professions with $32.7 \%, 23.2 \%$ from the emergency and ICU department respectively. Nurses constituted $28.2 \%$ of the professions with more than half of them working in the ICU department (58.8\%) and $37.3 \%$ working in the emergency department, and of the total study pharmacists; $80.8 \%$ worked in the hospital pharmacy. Most HCPs (43.6\%) had only one day of the week off. The mean working hours per week were $41 \pm 19.22$ hours/week for the whole sample.

\subsection{Prevalence of burnout among participants}

The majority of healthcare providers had high levels of work disengagement $(75.4 \%)$ and emotional exhaustion (98.6\%). Burnout syndrome was shown in $75 \%$ of the healthcare providers with $77 \%$ prevalence among the Egyptian HCPs and 71\% prevalence among the Sudanese HCPs (Table 2).

Table (3) shows the mean scores of the two domains of burnout. The mean score of disengagement for all HCPs of both countries was $2.56 \pm 0.53$, for Egypt $(2.65 \pm 0.57)$ and for Sudan $(2.47 \pm 0.47)$. The mean score of emotional exhaustion for all HCPs of both countries was $2.73 \pm 0.29$, for Egypt $(2.76 \pm$ $0.28)$ and for Sudan $(2.70 \pm 0.29)$. The mean score of overall burnout for all HCPs of both countries was $2.64 \pm 0.36$, for Egypt $(2.70 \pm 0.38)$ and for Sudan $(2.58 \pm 0.34)$.

\subsection{Factors associated with burnout syndrome among participants}

Among Egyptian HCPs, the educational qualification $(p=0.001)$ and profession $(p=<0.001)$ showed a statistically significant relation with the work disengagement mean scores. Age, profession and working hours per week showed a significant relation with emotional exhaustion mean scores $(p=0.004,0.020$, 0.046 respectively). While the overall burnout mean scores were statistically significantly related with age, educational qualification and the profession ( $p=0.015,0.002,<0.001$ respectively) (Table 4).

For Sudanese health care professionals, age showed a statistically significant relation with the work disengagement, the emotional exhaustion and the overall burnout mean scores $(p=0.009,<0.001,<0.001$ respectively) as well as the number of days off $(p=<0.001)$. There was a significant relation between educational qualifications and the work disengagement $(p=0.003)$ and overall burnout mean scores ( $p=$ 
0.003). While the mean scores of the emotional exhaustion were statistically significantly with the profession $(p=<0.001)$ (Table 5).

\subsection{Predictors of burnout syndrome among participants}

The analysis of factors affecting burnout was contextualized to each different setting using univariate and multivariate regression models. Table 6 shows that, among Egyptian HCPs, the independent parameters from the sociodemographic and work related characteristics that affected the burnout syndrome from the univariate regression analysis with statistical significance were educational qualifications ( $\beta=1.231, p=0.002)$, certain professions as doctors $(\beta=4.567, p=<0.001)$, nurses $(\beta=4.977$, $p=0.001)$, radiology technicians $(\beta=13.289, p=0.029)$ and the working hours per week $(\beta=0.046, p=$ 0.029). However, after adjusting age and all other independent variables the multivariate analysis showed that working hours was the only significant predictor for burnout syndrome among Egyptian HCPs where one hour increase in working hours per week is associated with 0.04 increase in levels of burnout domains $(\beta=0.044, p=0.031)$.

For Sudanese HCPs, the independent parameters from the univariate regression analysis that affected burnout syndrome with statistical significance were the age $(\beta=0.277, p=<0.001)$, educational qualification ( $\beta=1.162, p=0.038)$, professions such as pharmacists $(p=0.003)$, nurses $(\beta=2.038, p=$ $0.011)$, radiology technicians $(\beta=6.820, p=0.030)$ and the number of days off $(\beta=2.112, p=<0.001)$. After adjustment for all possible confounders, age as a predictor and number of days off as a protective factor were the only significant parameters affecting burnout syndrome in the multivariate analysis ( $\beta=$ $0.230,-2.155, p=0.022,<0.001$ respectively) where one year increase in age is associated with 0.23 increase in the levels of burnout domains (disengagement and emotional exhaustion). On the other hand, an increase of one day off is associated with a 2.1 decrease in the levels of burnout domains (Table 7).

\section{Discussion}

Since the emergence of COVID-19 pandemic, healthcare workers across the world played a pivotal role in treating COVID-19 patients and being in the frontline directly exposed to patients with a potentially significant burden to their own health and wellbeing. ${ }^{29}$ Compared to normal circumstances, there is a significant increase in pandemic-related burnout ${ }^{30}$ and the potential mental health impact of COVID-19 on frontline health professionals should be considered. The aim of the current study was to assess the extent of burnout among health professionals working in COVID-19 isolation facilities in Egypt and Sudan and to determine the associated sociodemographic and work characteristics.

Results of the current study revealed a high percentage of burnout in both countries, which was $77 \%$ among the Egyptian HCPs and 71\% among the Sudanese HCPs. These results were less than COVID-19 related burnout which was $89.1 \%$ among nurses working in a university hospital in Italy, ${ }^{31}$ which was conducted during the first wave of the COVID-19 pandemic in contrast to the current study which was 
conducted during the third wave of the COVID-19 pandemic. Moreover, the prevalence of burnout in the current study is less than reported prevalence among Egyptian ICU workers which was $87.4 \%{ }^{32}$. On the other hand, results of the current study were similar to results of other studies which showed $63 \%$ burnout prevalence in the UK, 71\% in Poland, 68\% in Singapore ${ }^{3}$ and $73 \%$ in Egypt $^{33}$. Current study findings were more than reported burnout prevalence among medical residents in Sao Paulo, Brazil which was $49 \%^{34}$ and more than the reported prevalence of $51 \%$ among healthcare professionals during an intercontinental survey from 33 countries during COVID-19 pandemic but the study was based on measuring only the exhaustion core domain of burnout ${ }^{35}$.

Differences in reported prevalence of burnout syndrome in the published literature during COVID-19 can be due to the situation of the pandemic at the time of data collection in each country, the method which was used for assessing burnout which was commonly the Maslach Burnout Inventory and some studies used Copenhagen Inventory and others. ${ }^{36}$, or the nature of the health system in different countries ${ }^{32}$. Other reasons that may explain the high prevalence of burnout in the current study is that being based on assessment of burnout syndrome among the HCPs working in the isolation facilities; the increased workload, increased psychological distress, the burden from the direct contact with COVID-19 patients, and the stress of dealing with a new emergent disease in addition to the fear of self-infection or infecting their relatives collectively can cause increased burnout levels in comparison to HCPs working in nonisolation health facilities. ${ }^{17,37,38}$ In addition to that, working among isolated patients are likely to experience multiple mental health problems and that many HCPs working at isolation facilities are withdrawn or suggested self-isolation after working on COVID-19 cases. ${ }^{39}$ Although this explanation was contradictory to other studies which stated that non-frontline HCPS show higher level of burnout and stress than frontline HCPS, explained by the isolation facilities are better organized and there is sense of more control while the fear of being exposed when the protocols and organizations do not seem well established is the situation in non-isolation facilities. ${ }^{40}$

A study conducted among Egyptian physicians working during COVID-19 pandemics in non-isolation health facilities revealed $36 \%$ burnout prevalence less than the current study using a different scale ${ }^{13}$. Reasons for this discrepancy could be clarified from a study that was conducted among Egyptian nurses working in one of the COVID-19 triage hospitals which showed that three quarters of nurses $(75.2 \%)$ had high occupational stress levels. The highest priority stressors that were reported were dealing with death and dying, having personal demands and fears, employing strict biosecurity measures and, the COVID-19 stigma ${ }^{41}$ Finally, the presence of workload as frontline health care facilities are faced with the early rush of COVID-19 cases being the specialized tertiary care facilities provided with all methods for the diagnosis and management of suspected and confirmed COVID-19 cases. $^{42}$

The prevalence of burnout among Sudanese HCPs participated in the present study was greater than that among Sudanese HCPs working at primary health care centers in Wad Madani Al-Kubra in Sudan during COVID-19 pandemic which was $45 \%$ using Maslach Burnout Inventory and conducted in a different setting. ${ }^{43}$ Another study concluded that more than half of HCPs working in Khartoum state 
hospitals showed high levels of stress. ${ }^{44}$ Due to the fragile health system in Sudan, political instability and economic meltdown; medical personnel have to work under high pressure in a very limited infrastructure, and as a sequel working under stress and pressure can be from the leading factors that makes health professionals more prone to burnout. ${ }^{44,45}$

In the current study, the majority of HCPs of both countries had high levels of disengagement $(75.4 \%)$ and emotional exhaustion (98.6\%) which is higher than the findings among the Italian nurses which showed high levels of exhaustion( $76 \%$ ) and disengagement (52\%). ${ }^{31}$ Our results were close to results of healthcare workers in Singapore which revealed 79.7\% disengagement and 75.3\% exhaustion with mean OLBI scores 2.38 and 2.50 for disengagement and exhaustion respectively ${ }^{4}$ close to the mean scores of the current study which were 2.56 and 2.73 for disengagement and exhaustion respectively. The mean score of burnout of all participants of the present study was $2.64 \pm 0.36$ consistent with frontline nurses working in COVID-19 wards in Iran hospitals where the mean score of burnout was $2.61 \pm 0.27 .{ }^{46}$

Age from 20-40 years was significantly associated with higher levels of emotional exhaustion among Egyptian study participants similar to findings of other studies ${ }^{13,32,38,47,48}$ and this was explained by study conducted by Dimitriu et al. (2020) that younger physicians are always more work loaded and faced continuously with unpredictable changes in duty schedules and cancelation of vacations. Others explained that older HCPs may have a better knowledge in comparison to the younger ones in coping with burnout. ${ }^{38}$ While other studies reasoned that young HCPs are more exposed to social media which is full of information about the pandemic, some necessary and some are unnecessary disturbing news that can be stressful. ${ }^{49}$ But this was not the condition among the study Sudanese participants as being older than 40 years was significantly associated with more levels of emotional exhaustion and supporting this results was that older practitioners fear more exposure risk to infection and occurrence of complications especially if they have underlying diseases. ${ }^{50}$

Educational qualification of the study HCPs was significantly associated with the levels of burnout domains similar to findings of other studies. ${ }^{33}$ The profession was significantly associated with levels of burnout and levels of emotional exhaustion among study participants similar to findings of other studies ${ }^{51}$ and the higher levels of burnout were among the study Egyptian physicians and pharmacists as well as Sudanese radiology technicians and pharmacists.

Increasing working hours per week was associated with higher levels of emotional exhaustion among Egyptian HCPs similar to that reported in Galván ${ }^{52}$ and Hathout ${ }^{42}$ studies and to the levels of patientrelated burnout reported among emergency physicians working $>40$ hours using Copenhagen tool. ${ }^{10}$ While the increasing hours were found not significantly different in another study. ${ }^{32}$ It was found that from the reasons behind the psychological consequences caused by the pandemic to HCPs were working more hours than usual that can be exceeded to making double shifts. As this may lead to disturbance of the circadian rhythm and the sleep-wake cycle of HCPs, job stress which can lead to malpractices and to an unsatisfactory job performance. Long working hours also causes more exposure to patients. ${ }^{38,42}$ Long 
working hours may have an impact on the social life and family of women HCPs and may result in the development of fear and guilt towards their families. ${ }^{13}$ Resting time is always needed to guarantee personal wellness and a proper job performance, ${ }^{53}$ as the inadequate leisure time appeared to from the major stressors and associated with a high level of burnout. ${ }^{32}$

Findings from the present study indicated that the significant parameter affecting burnout syndrome among Egyptian health professionals was working hours per week similar to results reported in another study. ${ }^{54}$ Evidently, the unsuitable working hours has greatly decreased provider satisfaction among this population, ${ }^{55}$ with the additional workload imposed by COVID-19 pandemic, it might has contributed to further decreased job satisfaction and increase the possibility of burnout development among participants. In accordance with this finding, a study among HCPs amid COVID-19 has found that working hours are significantly associated with burnout. ${ }^{56}$ Working hours were one of the independent significant factors associated with stress in other studies. ${ }^{57}$ While amongst Sudanese HCPs, participants' age was found to be positively associated with burnout and number of days off as a protective factor, a similar study among nurses concluded that age may be associated with reduced sense of achievement at work. ${ }^{58}$ Additionally, research on burnout showed that age followed a non-linear relationship with emotional exhaustion and total burnout. ${ }^{59}$ In support to our findings a study revealed that number of days is a potential protective factor against burnout. ${ }^{60}$

\section{Limitations}

The study followed a cross-sectional study design; hence, it's difficult to establish the causal association between the study variables and burnout syndrome. The baseline level of burnout before the pandemic was not assessed, comparing the changes in prevalence of burnout would have certainly added to this study. Moreover, the use of non-probability sampling in recruiting participants in the cross-sectional survey might have affected the representativeness of our sample and limits the generalization of study findings. Finally, the use of online survey introduced the risk of selection bias, favoring HCPs who had access to the internet connection. Despite these limitations, the study results are not inconsistent with published literature and were able to shed light on COVID-19 related mental health issues among this critical population.

\section{Conclusion}

The study revealed a high prevalence of burnout syndrome among HCWs working at COVID-19 isolation facilities in Egypt and Sudan. Appropriate action should be taken to preserve mental health status through establishment of effective and efficient coping strategies.

\section{Declarations}

\section{Ethics statement}


This study has been approved by Ethics Committee of High Institute of Public Health, Alexandria University, Egypt.

\section{Author's Contributions}

Noha EL Dabbah developed the study concept. Yasir Elhadi designed the data collection tool. All authors shared in data collection, participated in data analysis and in writing the manuscript. All authors have read and agreed to the final manuscript and approved the submitted version.

\section{Data availability statement}

The data supporting the current study findings are available from the corresponding author upon reasonable request.

ORCID

Noha Ahmed El Dabbah https://orcid.org/0000-0001-6321-9219

Yasir Ahmed Mohammed Elhadi https://orcid.org/0000-0003-3649-0374

\section{Acknowledgement}

All authors acknowledge and appreciate the considerable efforts and the immense sacrifices of all frontline health care professionals facing COVID 19 pandemic. We would like to extend our profound gratitude to Dr. Adrian Rabe and Dr. Ramy Shaaban for their assistance in this study.

\section{Funding}

None

\section{Conflict of interest}

The authors declare that they have no conflict of interest.

\section{References}

1. Cucinotta D, Vanelli M. WHO declares COVID-19 a pandemic. Acta Biomed. 2020;91(1):157-160. doi:10.23750/abm.v91i1.9397

2. Mehanna A, Elhadi YAM, Lucero-Prisno III DE. Public willingness to adhere to COVID-19 precautionary measures in Sudan: an application of the Health Belief Model. Pan Afr Med J. 2021;39. doi:10.11604/pamj.2021.39.135.29171 
3. Denning M, Goh ET, Tan B, et al. Determinants of burnout and other aspects of psychological wellbeing in healthcare workers during the Covid-19 pandemic: A multinational cross-sectional study. Brenner MH, ed. PLoS One. 2021;16(4):e0238666. doi:10.1371/journal.pone.0238666

4. Tan BYQ, Kanneganti A, Lim LJH, et al. Burnout and Associated Factors Among Health Care Workers in Singapore During the COVID-19 Pandemic. J Am Med Dir Assoc. 2020;21(12):1751-1758.e5. doi:10.1016/j.jamda.2020.09.035

5. Freudenberger HJ. Staff Burn-Out. J Soc Issues. 1974;30(1):159-165. doi:10.1111/j.15404560.1974.tb00706.x

6. Lee YY, Medford ARL, Halim AS. Burnout in physicians. J R Coll Physicians Edinb. 2015;45(2):104107. doi:10.4997/JRCPE.2015.203

7. Maslach C, Jackson S, Leiter M. Malasch Burnout Inventory (3rd edition). Eval Stress A B Resour Vol 1. Published online 1986:191-218.

8. Burn-out an "occupational phenomenon": International Classification of Diseases. Accessed April 18, 2021. https://www.who.int/news/item/28-05-2019-burn-out-an-occupational-phenomenoninternational-classification-of-diseases

9. Tipa RO, Tudose C, Pucarea VL. Measuring Burnout Among Psychiatric Residents Using the Oldenburg Burnout Inventory (OLBI) Instrument. J Med Life. 2019;12(4):354-360. doi:10.25122/jml-20190089

10. Abuzeyad F, Bashmi L, Das P, et al. Burnout and Stress Among Emergency Physicians in the Kingdom of Bahrain Using the Copenhagen Burnout Inventory (CBI) and Short Form-stress Overload Scale (SOS-S). Published online October 20, 2020. doi:10.21203/rs.3.rs-92193/v1

11. Lall MD, Gaeta TJ, Chung AS, et al. Assessment of physician well-being, part one: Burnout and other negative states. West J Emerg Med. 2019;20(2):278-290. doi:10.5811/westjem.2019.1.39665

12. Khamisa N, Peltzer K, llic D, Oldenburg B. Work related stress, burnout, job satisfaction and general health of nurses: A follow-up study. Int J Nurs Pract. 2016;22(6):538-545. doi:10.1111/ijn.12455

13. Abdelhafiz AS, Ali A, Ziady HH, Maaly AM, Alorabi M, Sultan EA. Prevalence, Associated Factors, and Consequences of Burnout Among Egyptian Physicians During COVID-19 Pandemic. Front Public Heal. 2020;8:864. doi:10.3389/fpubh.2020.590190

14. Morgantini LA, Naha $\mathrm{U}$, Wang $\mathrm{H}$, et al. Factors contributing to healthcare professional burnout during the COVID-19 pandemic: A rapid turnaround global survey. Murakami M, ed. PLoS One. 2020;15(9):e0238217. doi:10.1371/journal.pone.0238217 
15. Chemali Z, Ezzeddine FL, Gelaye B, et al. Burnout among healthcare providers in the complex environment of the Middle East: A systematic review. BMC Public Health. 2019;19(1). doi:10.1186/s12889-019-7713-1

16. Dugani S, Afari $\mathrm{H}$, Hirschhorn LR, et al. Prevalence and factors associated with burnout among frontline primary health care providers in low-and middle-income countries: A systematic review. Gates Open Res. 2018;2:4. doi:10.12688/gatesopenres.12779.3

17. Saleem Z, Majeed MM, Rafique S, et al. COVID-19 pandemic fear and anxiety among healthcare professionals in Pakistan. Published online June 23, 2020. doi:10.21203/rs.3.rs-37608/v1

18. Mohamed AS, DIA SA. Prevalence of burnout among African healthcare workers. South African J Public Heal (incorporating Strength Heal Syst. 2019;3(2):32. doi:10.1111/j.1540-4560.1974.tb00706.x

19. S F. Healthcare in Egypt: A Synopsis on the System and the Anticipated Reforms. World Hosp Health Serv. 2016;52(3):21-23. Accessed September 28, 2021.

https://europepmc.org/article/med/30707809

20. Wu Y, Wang J, Luo C, et al. A Comparison of Burnout Frequency Among Oncology Physicians and Nurses Working on the Frontline and Usual Wards During the COVID-19 Epidemic in Wuhan, China. J Pain Symptom Manage. 2020;60(1):e60-e65. doi:10.1016/j.jpainsymman.2020.04.008

21. Elhadi YAM, Mehanna A, Adebisi YA, et al. Willingness to Vaccinate against COVID-19 among Healthcare Workers: An Online Survey in 10 Countries in the Eastern Mediterranean Region. Glob J Health Sci. 2021;13(9):42. doi:10.5539/gjhs.v13n9p42

22. Demerouti E, Bakker AB, Vardakou I, Kantas A. The convergent validity of two burnout instruments: A multitrait-multimethod analysis. Eur J Psychol Assess. 2003;19(1):12-23.

doi:https://doi.org/10.1027/1015-5759.19.1.12

23. Bhugra D, Sauerteig SO, Bland D, et al. A descriptive study of mental health and wellbeing of doctors and medical students in the UK. Int Rev Psychiatry. 2019;31(7-8):563-568.

doi:10.1080/09540261.2019.1648621

24. Westwood S, Morison L, Allt J, Holmes N. Predictors of emotional exhaustion, disengagement and burnout among improving access to psychological therapies (IAPT) practitioners. J Ment Heal. 2017;26(2):172-179. doi:10.1080/09638237.2016.1276540

25. Peterson U, Demerouti E, Bergström G, Samuelsson M, Åsberg M, Nygren Å. Burnout and physical and mental health among Swedish healthcare workers. J Adv Nurs. 2008;62(1):84-95. doi:10.1111/j.1365-2648.2007.04580.x

26. Nwosu ADG, Ossai EN, Mba UC, et al. Physician burnout in Nigeria: a multicentre, cross-sectional study. BMC Health Serv Res. 2020;20(1):863. doi:10.1186/s12913-020-05710-8 
27. Card AJ. Burnout and sources of stress among healthcare risk managers and patient safety personnel during the covid-19 pandemic: A pilot study. Disaster Med Public Health Prep. Published online 2021. doi:10.1017/dmp.2021.120

28. Gliem JA, Gliem RR. Midwest Research to Practice Conference in Adult, Continuing, and Community Education. Midwest Research-to-Practice Conference in Adult, Continuing, and Community Education; 2003. Accessed September 28, 2021. https://scholarworks.iupui.edu/handle/1805/344

29. Billings J, Ching BCF, Gkofa V, Greene T, Bloomfield M. Healthcare workers' experiences of working on the frontline and views about support during COVID-19 and comparable pandemics: A rapid review and meta-synthesis. medRxiv. Published online June 23, 2020:2020.06.21.20136705. doi:10.1101/2020.06.21.20136705

30. Khasne RW, Dhakulkar BS, Mahajan HC, Kulkarni AP. Burnout among healthcare workers during COVID-19 pandemic in india: Results of a questionnaire-based survey. Indian J Crit Care Med. 2020;24(8):664-671. doi:10.5005/jp-journals-10071-23518

31. Bellanti F, Lo Buglio A, Capuano E, et al. Factors Related to Nurses' Burnout during the First Wave of Coronavirus Disease-19 in a University Hospital in Italy. Int $J$ Environ Res Public Health. 2021;18(10):5051. doi:10.3390/ijerph18105051

32. Abbas, Ali A, Bahgat SM, Shouman W. Prevalence, associated factors, and consequences of burnout among ICU healthcare workers: an Egyptian experience. Egypt J Chest Dis Tuberc. 2019;68(4):514. doi:10.4103/EJCDT.EJCDT_188_18

33. Omar DI, Hani BM, Abd-Ellatif EE. Burnout among Physicians in Egypt during COVID-19 Pandemic. Egypt J Hosp Med. 2021;82(4):599-608. doi:10.21608/ejhm.2021.150385

34. Mendonça VS, Steil A, Teixeira de Gois AF. COVID-19 pandemic in São Paulo: a quantitative study on clinical practice and mental health among medical residency specialties. Sao Paulo Med J. 2021;139(5):489-495. doi:10.1590/1516-3180.2021.0109.r1.27042021

35. Morgantini LA, Naha $\mathrm{U}$, Wang $\mathrm{H}$, et al. Factors contributing to healthcare professional burnout during the COVID-19 pandemic: A rapid turnaround global survey. Murakami M, ed. PLoS One. 2020;15(9):e0238217. doi:10.1371/journal.pone.0238217

36. Amanullah S, Shankar RR. The impact of covid-19 on physician burnout globally: A review. Healthc. 2020;8(4). doi:10.3390/healthcare8040421

37. Dai Y, Hu G, Xiong H, Qiu H, Yuan X. Psychological impact of the coronavirus disease 2019 (COVID19) outbreak on healthcare workers in China. medRxiv. Published online March 6 , 2020:2020.03.03.20030874. doi:10.1101/2020.03.03.20030874 
38. H. Alanazi K, M. bin Saleh G, M. AlEidi S, A. AlHarbi M, M. Hathout H. Prevalence and Risk Factors of Burnout among Healthcare Professionals during COVID-19 Pandemic - Saudi Arabia. Am J Public Heal Res. 2020;9(1):18-27. doi:10.12691/ajphr-9-1-3

39. Sultana A, Sharma R, Hossain MM, Bhattacharya S, Purohit N. Burnout among healthcare providers during COVID-19: Challenges and evidence-based interventions. Indian J Med Ethics. 2020;05(04):308-311. doi:10.20529/ijme.2020.73

40. Dimitriu MCT, Pantea-Stoian A, Smaranda AC, et al. Burnout syndrome in Romanian medical residents in time of the COVID-19 pandemic. Med Hypotheses. 2020;144. doi:10.1016/j.mehy.2020.109972

41. Said RM, El-Shafei DA. Occupational stress, job satisfaction, and intent to leave: nurses working on front lines during COVID-19 pandemic in Zagazig City, Egypt. Environ Sci Pollut Res. 2021;28(7):87918801. doi:10.1007/s11356-020-11235-8

42. Hathout H, El-Esrigy F, Farag N, El Dalatony M. PSYCHOLOGICAL IMPACT OF COVID-19 PANDEMIC ON HEALTH CARE WORKERS. Egypt J Occup Med. 2021;45(2):33-50. doi:10.21608/ejom.2021.170561

43. Ahmed DMM, Abdulhamid DOH, Suleiman DIEE. The Prevalence and Factors associated with Burnout among Sudanese Health Care Professionals at Primary Health Care Centers in Wad Madani AlKubra (Sudan), and Sharjah (UAE), 20 October - 20 November 2020. Acad J Res Sci Publ. 2021;3(26):527. doi:10.52132/ajrsp.e.2021.261

44. Mahgoub IM, Abdelrahman A, Abdallah TA, et al. Psychological effects of the COVID-19 pandemic: Perceived stress, anxiety, work-family imbalance, and coping strategies among healthcare professionals in Khartoum state hospitals, Sudan, 2021. Brain Behav. 2021;11(8). doi:10.1002/brb3.2318

45. Elhadi YAM, Adebisi YA, Hassan KF, Mohammed SEE, Lin X, Lucero-Prisno III DE. The formidable task of fighting COVID-19 in Sudan. Pan Afr Med J. 2020;35. doi:10.11604/pamj.supp.2020.35.2.24984

46. Hoseinabadi TS, Kakhki S, Teimori G, Nayyeri S. Burnout and its influencing factors between frontline nurses and nurses from other wards during the outbreak of Coronavirus Disease-COVID-19-in Iran. Investig y Educ en Enferm. 2020;38(2). doi:10.17533/UDEA.IEE.V38N2E03

47. Abdelghani M, El-Gohary HM, Fouad E, Hassan MS. Addressing the relationship between perceived fear of COVID-19 virus infection and emergence of burnout symptoms in a sample of Egyptian physicians during COVID-19 pandemic: a cross-sectional study. Middle East Curr Psychiatry. 2020;27(1). doi:10.1186/s43045-020-00079-0

48. Elsheikh, Naga AE. Burnout among Egyptian health care workers and its associations. Egypt J Psychiatry. 2021;42(1):43. doi:10.4103/EJPSY.EJPSY_46_20 
49. Al-Hanawi MK, Mwale ML, Alshareef N, et al. <p>Psychological Distress Amongst Health Workers and the General Public During the COVID-19 Pandemic in Saudi Arabia</p>. Risk Manag Healthc Policy. 2020;Volume 13:733-742. doi:10.2147/RMHP.S264037

50. Xing J, Sun N, Xu J, Geng S, Li Y. Study of the mental health status of medical personnel dealing with new coronavirus pneumonia. Doering S, ed. PLoS One. 2020;15(5):e0233145.

doi:10.1371/journal.pone.0233145

51. Odonkor ST, Frimpong K. Burnout among Healthcare Professionals in Ghana: A Critical Assessment. Biomed Res Int. 2020;2020. doi:10.1155/2020/1614968

52. Galván ME, Vassallo JC, Rodríguez SP, et al. Professional burnout in pediatric intensive care units in Argentina. Arch Argent Pediatr. 2012;110(6):466-473. doi:10.1590/S0325-00752012000600003

53. Rodríguez BO, Sánchez TL. The psychosocial impact of COVID-19 on health care workers. Int Braz J Urol. 2020;46(suppl.1):195-200. doi:10.1590/S1677-5538.IBJU.2020.S124

54. Alrawashdeh HM, Al-Tammemi AB, Alzawahreh MK, et al. Occupational burnout and job satisfaction among physicians in times of COVID-19 crisis: a convergent parallel mixed-method study. BMC Public Health. 2021;21(1):811. doi:10.1186/s12889-021-10897-4

55. Abdel-Rahman AG, Meky F, Abdel Halim AWE, Allam MF. Low Job Satisfaction Among Physicians in Egypt -. TAF Prev Med Bull. 2008;7(2):91-96.

56. Lin RT, Lin YT, Hsia YF, Kuo CC. Long working hours and burnout in health care workers: Non-linear dose-response relationship and the effect mediated by sleeping hours-A cross-sectional study. J Occup Health. 2021;63(1):e12228. doi:10.1002/1348-9585.12228

57. Dalatony M El. Stress and Burnout among Nurses working in Menoufia University Hospitals. Arch Nurs Care. 2018;1(1):24-25.

58. Mefoh PC, Ude EN, Chukwuorji JBC. Age and burnout syndrome in nursing professionals: moderating role of emotion-focused coping. Psychol Heal Med. 2019;24(1):101-107. doi:10.1080/13548506.2018.1502457

59. Marchand A, Blanc ME, Beauregard N. Do age and gender contribute to workers' burnout symptoms? Occup Med (Chic III). 2018;68(6):405-411. doi:10.1093/OCCMED/KQY088

60. Wisetborisut A, Angkurawaranon C, Jiraporncharoen W, Uaphanthasath R, Wiwatanadate P. Shift work and burnout among health care workers. Occup Med (Chic III). 2014;64(4):279-286. doi:10.1093/occmed/kqu009

\section{Tables}


Table (1): Distribution of healthcare professionals working in COVID-19 isolation facilities according to their socio demographic and working characteristics in Egypt and Sudan, 2021 


\begin{tabular}{|c|c|c|c|c|}
\hline \multicolumn{2}{|c|}{ Socio demographic characteristics } & \multirow{2}{*}{$\begin{array}{l}\text { Total } \\
(362) \\
\text { No. (\%) }\end{array}$} & \multicolumn{2}{|c|}{ Nationality } \\
\hline & & & $\begin{array}{c}\text { Egypt } \\
\text { (181) } \\
\text { No. (\%) }\end{array}$ & $\begin{array}{l}\text { Sudan } \\
\text { (181) } \\
\text { No. (\%) }\end{array}$ \\
\hline \multicolumn{5}{|l|}{ Age (years) } \\
\hline \multicolumn{2}{|l|}{$20-<40$} & $\begin{array}{c}293 \\
(80.9 \%)\end{array}$ & $\begin{array}{c}118 \\
(65.2 \%)\end{array}$ & $\begin{array}{c}175 \\
(96.7 \%)\end{array}$ \\
\hline \multicolumn{2}{|l|}{$40-<60+$} & $\begin{array}{c}69 \\
(19.1 \%)\end{array}$ & $\begin{array}{c}63 \\
(34.8 \%)\end{array}$ & $6(3.3 \%)$ \\
\hline \multicolumn{2}{|c|}{ Mean \pm SD } & $\begin{array}{c}31.84 \pm \\
8.32\end{array}$ & $\begin{array}{c}37.0 \pm \\
7.55\end{array}$ & $\begin{array}{c}26.67 \pm \\
5.31\end{array}$ \\
\hline \multicolumn{5}{|l|}{ Sex } \\
\hline \multicolumn{2}{|l|}{ Male } & $\begin{array}{c}145 \\
(40.1 \%)\end{array}$ & $\begin{array}{c}63 \\
(34.8 \%)\end{array}$ & $\begin{array}{c}82 \\
(45.3 \%)\end{array}$ \\
\hline \multicolumn{2}{|l|}{ Female } & $\begin{array}{c}217 \\
(59.9 \%)\end{array}$ & $\begin{array}{c}118 \\
(65.2 \%)\end{array}$ & $\begin{array}{c}99 \\
(54.7 \%)\end{array}$ \\
\hline \multicolumn{5}{|c|}{ Marital Status } \\
\hline \multicolumn{2}{|l|}{ Single } & $\begin{array}{c}182 \\
(50.3 \%)\end{array}$ & $\begin{array}{c}40 \\
(22.1 \%)\end{array}$ & $\begin{array}{c}142 \\
(78.5 \%)\end{array}$ \\
\hline \multicolumn{2}{|l|}{ Married } & $\begin{array}{c}171 \\
(47.2 \%)\end{array}$ & $\begin{array}{c}134 \\
(74.0 \%)\end{array}$ & $\begin{array}{c}37 \\
(20.4 \%)\end{array}$ \\
\hline \multicolumn{2}{|c|}{ Divorced / widowed } & $\begin{array}{c}9 \\
(2.5 \%)\end{array}$ & $\begin{array}{c}7 \\
(3.9 \%)\end{array}$ & $2(1.1 \%)$ \\
\hline \multicolumn{5}{|c|}{ Educational Qualification } \\
\hline \multicolumn{2}{|l|}{ Diploma } & $\begin{array}{c}17 \\
(4.7 \%)\end{array}$ & $\begin{array}{c}12 \\
(6.6 \%)\end{array}$ & $5(2.8 \%)$ \\
\hline \multicolumn{2}{|l|}{ Bachelor } & $\begin{array}{c}199 \\
(55.0 \%)\end{array}$ & $\begin{array}{c}45 \\
(24.9 \%)\end{array}$ & $\begin{array}{c}154 \\
(85.1 \%)\end{array}$ \\
\hline \multicolumn{2}{|c|}{ Postgraduate Diploma } & $\begin{array}{c}38 \\
(10.5 \%)\end{array}$ & $\begin{array}{c}34 \\
(18.8 \%)\end{array}$ & $4(2.2 \%)$ \\
\hline \multicolumn{2}{|c|}{ Master's/Fellowship } & $\begin{array}{c}88 \\
(24.3 \%)\end{array}$ & $\begin{array}{c}74 \\
(40.9 \%)\end{array}$ & $\begin{array}{c}14 \\
(7.7 \%)\end{array}$ \\
\hline \multicolumn{2}{|l|}{$\mathrm{PhD}$} & $\begin{array}{c}20 \\
(5.5 \%)\end{array}$ & $\begin{array}{c}16 \\
(8.8 \%)\end{array}$ & $4(2.2 \%)$ \\
\hline \multicolumn{5}{|c|}{ Work characteristics } \\
\hline \multicolumn{5}{|c|}{\begin{tabular}{l|l} 
Profession & Department
\end{tabular}} \\
\hline $\begin{array}{c}\text { Doctors } \\
211\end{array}$ & ICU & $\begin{array}{c}49 \\
(23.2 \%)\end{array}$ & $\begin{array}{c}33 \\
(23.6 \%)\end{array}$ & $\begin{array}{c}16 \\
(22.5 \%)\end{array}$ \\
\hline
\end{tabular}




\begin{tabular}{|c|c|c|c|c|}
\hline \multirow{4}{*}{$(58.3 \%)$} & Surgery & $\begin{array}{c}15 \\
(7.1 \%)\end{array}$ & $\begin{array}{c}9 \\
(6.4 \%)\end{array}$ & $6(8.5 \%)$ \\
\hline & Internal medicine & $\begin{array}{c}40 \\
(19.0 \%)\end{array}$ & $\begin{array}{c}25 \\
(17.9 \%)\end{array}$ & $\begin{array}{c}15 \\
(21.1 \%)\end{array}$ \\
\hline & Emergency & $\begin{array}{c}69 \\
(32.7 \%)\end{array}$ & $\begin{array}{c}39 \\
(27.9 \%)\end{array}$ & $\begin{array}{c}30 \\
(42.3 \%)\end{array}$ \\
\hline & $\begin{array}{l}\text { Others ( Pediatric, anesthesia, chest, clinical pathology, } \\
\text { obstetrics \& gynecology, radiology) }\end{array}$ & $\begin{array}{c}38 \\
(18.0 \%)\end{array}$ & $\begin{array}{c}34 \\
(24.3 \%)\end{array}$ & $4(5.6 \%)$ \\
\hline \multirow[t]{2}{*}{$\begin{array}{c}\text { Pharmacists } \\
26(7.2 \%)\end{array}$} & Clinical Pharmacy & $\begin{array}{c}5 \\
(19.2 \%)\end{array}$ & $\begin{array}{c}5 \\
(38.5 \%)\end{array}$ & $0(0.0 \%)$ \\
\hline & Hospital Pharmacy & $\begin{array}{c}21 \\
(80.8 \%)\end{array}$ & $\begin{array}{c}8 \\
(61.5 \%)\end{array}$ & $\begin{array}{c}13 \\
(100.0 \%)\end{array}$ \\
\hline \multirow{3}{*}{$\begin{array}{c}\text { Nurses } \\
102 \\
(28.2 \%)\end{array}$} & ICU & $\begin{array}{c}60 \\
(58.8 \%)\end{array}$ & $\begin{array}{c}12 \\
(70.6 \%)\end{array}$ & $\begin{array}{c}48 \\
(56.5 \%)\end{array}$ \\
\hline & Emergency & $\begin{array}{c}38 \\
(37.3 \%)\end{array}$ & $\begin{array}{c}1 \\
(5.9 \%)\end{array}$ & $\begin{array}{c}37 \\
(43.5 \%)\end{array}$ \\
\hline & Others & $\begin{array}{c}4 \\
(3.9 \%)\end{array}$ & $\begin{array}{c}4 \\
(23.5 \%)\end{array}$ & $0(0.0 \%)$ \\
\hline \multicolumn{2}{|c|}{ Lab technician } & $\begin{array}{c}13 \\
(3.6 \%)\end{array}$ & $\begin{array}{c}6 \\
(3.3 \%)\end{array}$ & $7(3.9 \%)$ \\
\hline \multicolumn{2}{|c|}{ Radiology technician } & $\begin{array}{c}4 \\
(1.1 \%)\end{array}$ & $\begin{array}{c}1 \\
(0.6 \%)\end{array}$ & $3(1.7 \%)$ \\
\hline \multicolumn{2}{|c|}{ Others ( Health care quality, infection control \& administrative positions) } & $\begin{array}{c}6 \\
(1.7 \%)\end{array}$ & $\begin{array}{c}4 \\
(2.2 \%)\end{array}$ & $2(1.1 \%)$ \\
\hline \multicolumn{5}{|l|}{ Days off } \\
\hline \multicolumn{2}{|l|}{1 day } & $\begin{array}{c}158 \\
(43.6 \%)\end{array}$ & $\begin{array}{c}94 \\
(51.9 \%)\end{array}$ & $\begin{array}{c}64 \\
(35.4 \%)\end{array}$ \\
\hline \multicolumn{2}{|l|}{2 days } & $\begin{array}{c}113 \\
(31.2 \%)\end{array}$ & $\begin{array}{c}55 \\
(30.4 \%)\end{array}$ & $\begin{array}{c}58 \\
(32.0 \%)\end{array}$ \\
\hline \multicolumn{2}{|c|}{3 days or more } & $\begin{array}{c}91 \\
(25.1 \%)\end{array}$ & $\begin{array}{c}32 \\
(17.7 \%)\end{array}$ & $\begin{array}{c}59 \\
(32.6 \%)\end{array}$ \\
\hline \multicolumn{5}{|c|}{ Working hours /Week } \\
\hline \multicolumn{2}{|l|}{$<36$} & $\begin{array}{c}106 \\
(29.3 \%)\end{array}$ & $\begin{array}{c}53 \\
(29.3 \%)\end{array}$ & $\begin{array}{c}53 \\
(29.3 \%)\end{array}$ \\
\hline \multicolumn{2}{|l|}{$36-<42$} & $\begin{array}{c}122 \\
(33.7 \%)\end{array}$ & $\begin{array}{c}63 \\
(34.8 \%)\end{array}$ & $\begin{array}{c}59 \\
(32.6 \%)\end{array}$ \\
\hline \multicolumn{2}{|l|}{$\geq 42$} & $\begin{array}{c}134 \\
(37.0 \%)\end{array}$ & $\begin{array}{c}65 \\
(35.9 \%)\end{array}$ & $\begin{array}{c}69 \\
(38.1 \%)\end{array}$ \\
\hline
\end{tabular}


Table (2): Distribution of healthcare professionals working at COVID-19 isolation facilities according to levels of burnout domains in Egypt and Sudan, 2021

\begin{tabular}{|c|c|c|c|}
\hline \multirow[t]{2}{*}{ Burnout syndrome } & \multirow{2}{*}{$\begin{array}{c}\text { Total } \\
(\mathrm{n}=362)\end{array}$} & \multicolumn{2}{|c|}{ Nationality } \\
\hline & & $\begin{array}{c}\text { Egypt } \\
(\mathrm{n}=181)\end{array}$ & $\begin{array}{l}\text { Sudan } \\
(\mathrm{n}=181)\end{array}$ \\
\hline \multicolumn{4}{|l|}{ Disengagement } \\
\hline Low & $89(24.6 \%)$ & $38(21.0 \%)$ & $51(28.2 \%)$ \\
\hline High & $273(75.4 \%)$ & $143(79.0 \%)$ & $130(71.8 \%)$ \\
\hline \multicolumn{4}{|l|}{ Exhaustion } \\
\hline Low & $5(1.4 \%)$ & $3(1.7 \%)$ & $2(1.1 \%)$ \\
\hline High & 357 (98.6\%) & $178(98.3 \%)$ & 179 (98.9\%) \\
\hline \multicolumn{4}{|l|}{ Overall burnout } \\
\hline Non-burnout & $4(1.1 \%)$ & $3(1.7 \%)$ & $1(0.6 \%)$ \\
\hline Disengaged & $1(0.3 \%)$ & $0(0.0 \%)$ & $1(0.6 \%)$ \\
\hline Exhausted & $85(23.5 \%)$ & $35(19.3 \%)$ & $50(27.6 \%)$ \\
\hline Burnout & $272(75.1 \%)$ & $143(79.0 \%)$ & $129(71.3 \%)$ \\
\hline
\end{tabular}

Table (3): Mean scores of burnout syndrome among healthcare professionals working at COVID-19 isolation facilities in Egypt and Sudan, 2021

\begin{tabular}{|c|c|c|c|c|c|c|}
\hline Mean score of burnout domains & \multicolumn{2}{|c|}{ Total (n=362) } & \multicolumn{4}{c|}{ Nationality } \\
\cline { 4 - 7 } & \multicolumn{2}{|c|}{} & \multicolumn{2}{c|}{ Egypt(n = 181) } & \multicolumn{2}{c|}{ Sudan(n = 181) } \\
\cline { 2 - 7 } & Mean \pm SD. & Median & Mean \pm SD. & Median & Mean \pm SD. & Median \\
\hline Mean score of disengagement & $2.56 \pm 0.53$ & 2.63 & $2.65 \pm 0.57$ & 2.75 & $2.47 \pm 0.47$ & 2.50 \\
\hline Mean score of exhaustion & $2.73 \pm 0.29$ & 2.75 & $2.76 \pm 0.28$ & 2.75 & $2.70 \pm 0.29$ & 2.75 \\
\hline Mean score of overall of burnout & $2.64 \pm 0.36$ & 2.63 & $2.70 \pm 0.38$ & 2.75 & $2.58 \pm 0.34$ & 2.56 \\
\hline
\end{tabular}

Table (4): Relation between burnout syndrome and the socio demographic and work characteristics of healthcare professionals working at COVID-19 isolation facilities in Egypt, 2021 


\begin{tabular}{|c|c|c|c|c|}
\hline \multirow[t]{2}{*}{ Socio demographic characteristics } & \multirow[t]{2}{*}{$\mathbf{N}$} & Disengagement & Exhaustion & Overall burnout \\
\hline & & Mean \pm SD & Mean \pm SD & Mean \pm SD \\
\hline \multicolumn{5}{|l|}{ Age (years) } \\
\hline $20-<40$ & 118 & $21.61 \pm 4.68$ & $22.41 \pm 2.02$ & $44.02 \pm 5.91$ \\
\hline $40-<60+$ & 63 & $20.32 \pm 4.33$ & $21.40 \pm 2.52$ & $41.71 \pm 6.22$ \\
\hline$t(p)$ & & $1.817(0.071)$ & $2.933^{*}\left(0.004^{*}\right)$ & $2.453^{*}\left(0.015^{*}\right)$ \\
\hline \multicolumn{5}{|l|}{ Sex } \\
\hline Male & 63 & $20.84 \pm 5.12$ & $22.03 \pm 2.43$ & $42.87 \pm 6.95$ \\
\hline Female & 118 & $21.33 \pm 4.29$ & $22.07 \pm 2.16$ & $43.40 \pm 5.62$ \\
\hline$t(p)$ & & $0.682(0.496)$ & $0.102(0.919)$ & $0.551(0.582)$ \\
\hline \multicolumn{5}{|l|}{ Marital Status } \\
\hline Single & 40 & $21.47 \pm 4.86$ & $22.0 \pm 2.25$ & $43.47 \pm 6.13$ \\
\hline Married & 134 & $21.01 \pm 4.52$ & $22.09 \pm 2.26$ & $43.10 \pm 6.12$ \\
\hline Divorced / widowed & 7 & $22.29 \pm 4.79$ & $21.71 \pm 2.50$ & $44.0 \pm 6.35$ \\
\hline$F(p)$ & & $0.376(0.687)$ & $0.107(0.899)$ & $0.118(0.889)$ \\
\hline \multicolumn{5}{|l|}{ Qualification } \\
\hline Diploma & 12 & $16.42 \pm 5.57$ & $20.75 \pm 3.05$ & $37.17 \pm 7.64$ \\
\hline Bachelor & 45 & $20.62 \pm 4.82$ & $22.18 \pm 2.07$ & $42.80 \pm 6.02$ \\
\hline Postgraduate Diploma & 34 & $20.94 \pm 3.84$ & $21.74 \pm 2.44$ & $42.68 \pm 5.64$ \\
\hline Master's/Fellowship & 74 & $22.31 \pm 4.17$ & $22.36 \pm 2.08$ & $44.68 \pm 5.53$ \\
\hline $\mathrm{PhD}$ & 16 & $21.38 \pm 4.40$ & $21.94 \pm 2.29$ & $43.31 \pm 6.11$ \\
\hline$F(p)$ & & $4.951^{*}\left(0.001^{*}\right)$ & $1.593(0.178)$ & $4.445^{*}\left(0.002^{*}\right)$ \\
\hline \multicolumn{5}{|l|}{ Profession } \\
\hline Doctors & 140 & $22.05 \pm 4.17$ & $22.20 \pm 2.14$ & $44.25 \pm 5.67$ \\
\hline Pharmacists & 13 & $20.15 \pm 4.67$ & $22.77 \pm 2.45$ & $42.92 \pm 5.82$ \\
\hline Nurses & 17 & $17.29 \pm 4.10$ & $21.41 \pm 2.27$ & $38.71 \pm 5.01$ \\
\hline Lab technician & 6 & $17.83 \pm 5.00$ & $21.33 \pm 1.51$ & $39.17 \pm 5.78$ \\
\hline Radiology technician & 1 & 13.0 & 17.0 & 30.0 \\
\hline Others & 4 & $16.75 \pm 6.50$ & $19.75 \pm 3.86$ & $36.50 \pm 10.08$ \\
\hline$F(p)$ & & $6.438^{*}\left(<0.001^{*}\right)$ & $2.750^{*}\left(0.020^{*}\right)$ & $5.784^{*}\left(<0.001^{*}\right)$ \\
\hline \multicolumn{5}{|l|}{ Days off } \\
\hline 1 day & 94 & $20.53 \pm 4.88$ & $21.86 \pm 2.52$ & $42.39 \pm 6.57$ \\
\hline
\end{tabular}




\begin{tabular}{|c|c|c|c|c|}
\hline 2 days & 55 & $21.58 \pm 3.78$ & $22.31 \pm 1.84$ & $43.89 \pm 5.00$ \\
\hline 3 days or more & 32 & $22.28 \pm 4.80$ & $22.19 \pm 2.05$ & $44.47 \pm 6.21$ \\
\hline$F(p)$ & & $2.093(0.126)$ & $0.749(0.474)$ & $1.884(0.155)$ \\
\hline \multicolumn{5}{|l|}{ Working hours /Week } \\
\hline$<36$ & 53 & $20.34 \pm 4.19$ & $21.51 \pm 2.14$ & $41.85 \pm 5.53$ \\
\hline $36-<42$ & 63 & $21.33 \pm 4.76$ & $22.02 \pm 2.42$ & $43.35 \pm 6.43$ \\
\hline$\geq 42$ & 65 & $21.66 \pm 4.71$ & $22.54 \pm 2.09$ & $44.20 \pm 6.10$ \\
\hline$F(p)$ & & $1.284(0.279)$ & $3.133^{*}\left(0.046^{*}\right)$ & $2.221(0.112)$ \\
\hline
\end{tabular}

t: Student t-test

F: F for ANOVA test

*: Statistically significant at $p \leq 0.05$

Table (5): Relation between burnout syndrome and the socio demographic and work characteristics of healthcare professionals working at COVID-19 isolation facilities in Sudan, 2021 


\begin{tabular}{|c|c|c|c|c|}
\hline \multirow[t]{2}{*}{ Socio demographic characteristics } & \multirow[t]{2}{*}{$\mathbf{N}$} & Disengagement & Exhaustion & Overall burnout \\
\hline & & Mean \pm SD & Mean \pm SD & Mean \pm SD. \\
\hline \multicolumn{5}{|l|}{ Age (years) } \\
\hline $20-<40$ & 175 & $19.59 \pm 3.70$ & $21.43 \pm 2.19$ & $41.02 \pm 5.20$ \\
\hline $40-<60+$ & 6 & $23.67 \pm 4.08$ & $25.50 \pm 1.76$ & $49.17 \pm 5.71$ \\
\hline$t(p)$ & & $2.649^{*}\left(0.009^{*}\right)$ & $4.498^{*}\left(<0.001^{*}\right)$ & $3.761^{*}\left(<0.001^{*}\right)$ \\
\hline \multicolumn{5}{|l|}{ Sex } \\
\hline Male & 82 & $19.91 \pm 3.54$ & $21.78 \pm 2.43$ & $41.70 \pm 5.09$ \\
\hline Female & 99 & $19.57 \pm 3.96$ & $21.39 \pm 2.16$ & $40.96 \pm 5.65$ \\
\hline$t(p)$ & & $0.619(0.537)$ & $1.131(0.260)$ & $0.911(0.363)$ \\
\hline \multicolumn{5}{|l|}{ Marital Status } \\
\hline Single & 142 & $19.65 \pm 3.76$ & $21.59 \pm 2.17$ & $41.25 \pm 5.30$ \\
\hline Married & 37 & $19.92 \pm 3.93$ & $21.51 \pm 2.68$ & $41.43 \pm 5.93$ \\
\hline Divorced / widowed & 2 & $21.0 \pm 0.0$ & $21.0 \pm 4.24$ & $42.0 \pm 4.24$ \\
\hline$F(p)$ & & $0.186(0.830)$ & $0.079(0.924)$ & $0.034(0.966)$ \\
\hline \multicolumn{5}{|l|}{ Qualification } \\
\hline Diploma & 5 & $22.0 \pm 5.00$ & $22.00 \pm 2.45$ & $44.0 \pm 6.48$ \\
\hline Bachelor & 154 & $19.47 \pm 3.55$ & $21.47 \pm 2.18$ & $40.94 \pm 5.08$ \\
\hline Postgraduate Diploma & 4 & $15.50 \pm 4.93$ & $19.50 \pm 2.38$ & $35.0 \pm 6.63$ \\
\hline Master's/Fellowship & 14 & $22.43 \pm 4.05$ & $22.71 \pm 2.67$ & $45.14 \pm 6.06$ \\
\hline PhD & 4 & $21.50 \pm 2.65$ & $23.00 \pm 3.56$ & $44.50 \pm 4.43$ \\
\hline$F(p)$ & & $4.190^{*}\left(0.003^{*}\right)$ & $2.263(0.064)$ & $4.257^{*}\left(0.003^{*}\right)$ \\
\hline \multicolumn{5}{|l|}{ Profession } \\
\hline Doctors & 71 & $19.97 \pm 3.47$ & $21.75 \pm 2.48$ & $41.72 \pm 5.07$ \\
\hline Pharmacists & 13 & $22.08 \pm 5.01$ & $23.54 \pm 2.63$ & $45.62 \pm 6.69$ \\
\hline Nurses & 85 & $19.21 \pm 3.74$ & $21.0 \pm 1.88$ & $40.21 \pm 5.16$ \\
\hline Lab technician & 7 & $18.14 \pm 3.58$ & $21.71 \pm 1.38$ & $39.86 \pm 4.81$ \\
\hline Radiology technician & 3 & $23.0 \pm 1.73$ & $25.0 \pm 1.73$ & $48.0 \pm 3.46$ \\
\hline Others & 2 & $18.0 \pm 1.41$ & $21.0 \pm 1.41$ & $39.00 \pm 0.0$ \\
\hline$F(p)$ & & $2.246(0.052)$ & $4.915^{*}\left(<0.001^{*}\right)$ & $3.804^{*}\left(0.003^{*}\right)$ \\
\hline \multicolumn{5}{|l|}{ Days off } \\
\hline 1 day & 64 & $20.56 \pm 3.45$ & $22.38 \pm 2.03$ & $42.94 \pm 4.68$ \\
\hline
\end{tabular}




\begin{tabular}{|c|c|c|c|c|}
\hline 2 days & 58 & $20.48 \pm 3.54$ & $21.66 \pm 2.52$ & $42.14 \pm 5.37$ \\
\hline 3 days or more & 59 & $18.07 \pm 3.85$ & $20.61 \pm 1.97$ & $38.68 \pm 5.27$ \\
\hline$F(p)$ & & $9.224^{*}\left(<0.001^{*}\right)$ & $10.100^{*}\left(<0.001^{*}\right)$ & $11.864^{*}\left(<0.001^{*}\right)$ \\
\hline \multicolumn{5}{|l|}{ Working hours /Week } \\
\hline$<36$ & 53 & $19.28 \pm 4.40$ & $21.23 \pm 2.59$ & $40.51 \pm 6.28$ \\
\hline $36-<42$ & 59 & $19.36 \pm 3.24$ & $21.39 \pm 2.03$ & $40.75 \pm 4.58$ \\
\hline$\geq 42$ & 69 & $20.38 \pm 3.63$ & $21.99 \pm 2.22$ & $42.36 \pm 5.22$ \\
\hline$F(p)$ & & $1.691(0.187)$ & $1.934(0.148)$ & $2.242(0.109)$ \\
\hline
\end{tabular}
t: Student $t$-test
F: F for ANOVA test
*: Statistically significant at $p \leq 0.05$

Table (6): Univariate and multivariate regression analysis for the parameters affecting burnout syndrome among healthcare professionals working at COVID-19 isolation facilities in Egypt, 2021

\begin{tabular}{|c|c|c|c|c|}
\hline \multirow{2}{*}{ Variables } & \multicolumn{2}{|c|}{ Univariate } & \multicolumn{2}{c|}{ \# Multivariate } \\
\cline { 2 - 5 } & P & B (95\%C.I) & p & (95\%C.I) \\
\hline Age (years) & 0.682 & $-0.025(-0.144-0.094)$ & & \\
\hline Marital Status & 0.582 & $0.525(-1.357-2.407)$ & & \\
\hline Qualification & 0.660 & $0.456(-1.589-2.502)$ & & \\
\hline Profession & $\mathbf{0 . 0 0 2}$ & $1.231(0.444-2.018)$ & 0.235 & $0.520(-0.342-1.383)$ \\
\hline Doctors & & & & \\
\hline Pharmacists & $<0.001^{*}$ & $4.567(2.532-6.602)$ & 0.404 & $1.390(-1.889-4.669)$ \\
\hline Nurses & 0.858 & $-0.315(-3.790-3.160)$ & & \\
\hline Lab technician & $0.001^{*}$ & $-4.977(-7.964--1.990)$ & 0.088 & $-3.620(-7.788-0.548)$ \\
\hline Radiology technician & $\mathbf{0 . 0 2 9 ^ { * }}$ & $-13.289(-25.234--1.344)$ & 0.335 & $-2.706(-8.226-2.814)$ \\
\hline Days off & 0.060 & $1.120(-0.048-2.288)$ & & \\
\hline Working hours /Week & $\mathbf{0 . 0 2 9 ^ { * }}$ & $0.046(0.005-0.088)$ & $0.031^{*}$ & $0.044(0.004-0.085)$ \\
\hline
\end{tabular}

$R^{2}=0.147, F=5.007^{*}, p<0.001^{*} \quad \beta:$ Unstandardized Coefficients

C.I: Confidence interval \#: All variables with $p<0.05$ was included in the multivariate *: Statistically significant at $p \leq 0.05$

Table (7): Univariate and multivariate regression analysis for the parameters affecting burnout syndrome among healthcare professionals working at COVID-19 isolation facilities in Sudan, 2021 


\begin{tabular}{|c|c|c|c|c|}
\hline \multirow{2}{*}{ Variables } & \multicolumn{2}{|c|}{ Univariate } & \multicolumn{2}{c|}{${ }^{\text {\# }}$ Multivariate } \\
\cline { 2 - 5 } & $\mathbf{P}$ & $\boldsymbol{\beta}$ (95\%C.I) & $\mathbf{p}$ & $\boldsymbol{\beta}$ (95\%C.I) \\
\hline Age (years) & $<0.001^{*}$ & $0.277(0.132-0.421)$ & $\mathbf{0 . 0 2 2 ^ { * }}$ & $0.230(0.034-0.426)$ \\
\hline Sex & 0.363 & $-0.736(-2.328-0.857)$ & & \\
\hline Marital Status & 0.861 & $-0.175(-2.146-1.795)$ & & \\
\hline Qualification & $\mathbf{0 . 0 3 8 ^ { * }}$ & $1.162(0.064-2.259)$ & 0.410 & $0.484(-0.673-1.641)$ \\
\hline Dofession & & & & \\
\hline Pharmacists & 0.396 & $0.700(-0.924-2.324)$ & & \\
\hline Nurses & $\mathbf{0 . 0 0 3 ^ { * }}$ & $4.657(1.657-7.657)$ & 0.076 & $2.653(-0.280-5.585)$ \\
\hline Lab technician & $\mathbf{0 . 0 1 1 ^ { * }}$ & $-2.038(-3.602--0.475)$ & 0.473 & $-0.584(-2.185-1.017)$ \\
\hline Radiology technician & $\mathbf{0 . 0 3 0 ^ { * }}$ & $6.820(0.678-12.962)$ & 0.552 & $2.199(-5.091-9.489)$ \\
\hline Days off & $<\mathbf{0 . 0 0 1 *}$ & $-2.112(-3.025--1.200)$ & $<0.001^{*}$ & $-2.155(-3.049--1.262)$ \\
\hline Working hours /Week & 0.918 & $0.002(-0.045-0.050)$ & & \\
\hline
\end{tabular}

$R^{2}=0.225, F=8.402^{*}, p<0.001^{*} \quad \beta:$ Unstandardized Coefficients \#: All variables with $p<0.05$ was included in the multivariate
C.I: Confidence interval *: Statistically significant at $p \leq 0.05$ 